\title{
FRACTURE RESISTANCE OF ENDODONTICALLY TREATED MAXILLARY PREMOLARS RESTORED WITH ENDOCROWNS WITH DIFFERENT PREPARATION DEPTH. IN VITRO STUDY
}

\author{
Amira Mohamed El-Sharkawy*
}

\begin{abstract}
Purpose: The aim of the study was to assess the effect of different endocrowns extensions inside the pulp chamber on the fracture resistance and failure mode of maxillary premolar.

Materials and methods: Twenty four single rooted upper premolars were root canal treated, arbitrarily divided into three main groups $(n=8)$ according to extension of endocrowns inside the pulp chamber $(\mathrm{GI}=2 \mathrm{~mm}, \mathrm{GII}=3 \mathrm{~mm}$ and $\mathrm{GIII}=4 \mathrm{~mm})$. Endocrowns were made-up from Brillient Crios (BC) CAD/CAM blocks and cemented with adhesive resin cement. Teeth were subjected to thermo-cycling and then to $45^{\circ}$ oblique compressive load until fracture. The fracture resistance and failure modes were determined. Data were analyzed with One Way ANOVA followed by Tukey`s post hoc test for multiple comparisons.
\end{abstract}

Results: The fracture resistances were significantly different between all groups; GII scored the highest mean fracture resistance value $(647 \pm 72.37 \mathrm{~N})$ followed by GI $(475.6 \pm 69.92 \mathrm{~N})$, and the lowest was scored by GIII $(353.9 \pm 61.02 \mathrm{~N})$. Regarding fracture analysis of different preparation depths; Gr I showed highest repairability percentage followed be Gr II and Gr III; there was significant difference between Gr (I) and Gr (II) and between Gr (I) and Gr (III) as P-value < 0.05 . While, there was insignificant difference between Gr (II) and Gr (III) as P-value $>0.05$ as revealed by Chi Square test.

Conclusion: Different extensions of endocrowns inside the pulp chamber affect the fracture resistance and failure mode of upper premolar.

\section{INTRODUCTION}

Restoring endodontically treated teeth with massive destruction of the coronal part is still a clinical challenge, particularly due to the loss of its strength after removing the pulp and surrounding dentine tissues. The retention of the restoration with those mutilated teeth is poor, so the use of intraradicular post and core to retain the crown is required. ${ }^{(1)}$

Even with all clinical success using intraradicular posts, there is a lot of drawbacks of this system; it requires removal of sound dentine from the root

\footnotetext{
* Associate Professor, Fixed Prosthodontics, Faculty of Dentistry, $6^{\text {th }}$ of October University, Giza, Egypt
} 
canal that makes it week and fragile, sometimes root fracture because of the incompatible modulus of elasticity with radicular dentin ${ }^{(2)}$. Moreover; in cases of curved, dilacerated and decalcified root; the placement of the post will be limited. As well separation of the composite core from the post in cases of fiber posts and root fracture risk in cases of metal post ${ }^{(3)}$.

An alternative restoration to endodontically treated teeth is the endocrown restorations. Bindl and Mormann ${ }^{(4)}$ were described the endocrown as adhesive restorations consisting of the entire core and crown as a single monolithic restoration. (i.e, monobloc). Endocrowns bonded to the pulp chamber and the cavity margins, consequently achieving macromechanical retention supplying by the axial opposing pulpal walls and micro-retention/chemical bonding attained with the usage of adhesive cementation . ${ }^{(4)}$

Restoring molars with endocrowns offer higher strength and fracture resistance during loading than molars restored with conventional post, core and crowns ${ }^{(5)}$. A 5-year clinical study reveal $87.1 \%$ of posterior teeth restored with endocrowns functioned perfectly without debonding or fracture ${ }^{(6)}$. Due to the advantages of endocrown on molarteeth, endocrowns should also be recommended for premolar teeth. In a clinical study, Bindl and Mörmann ${ }^{(7)}$ assessed the exhibition of 208 endocrowns on premolars and molars, and discovered that the premolars offered more failures due to adhesion loss Debonding of endocrowns on premolars is promoted to be due to the bonding area was smaller than molars, and the greater ratio of the prepared tooth structure to the overall crown might have caused a higher leverage for premolars than for molars. ${ }^{(8)}$ Moreover, maxillary premolars are subjected to more lateral forces, which may affect fracture resistance. ${ }^{[9]}$

Another attention is the use of innovative and flexible composite CAD/CAM milling blocks reinforced by nanoceramics as an alternative to ceramic ones that were firstly designated for endocrown ${ }^{[9]}$. Brilliant Crios (BC) is a reinforced composite material with an inorganic filler $(71 \%$ by weight) holding less than 20 - $\mu \mathrm{m}$ silica and less than $1-\mu \mathrm{m}$ barium glass ${ }^{(10)}$. Contrasting traditional composites, CAD/CAM composites are polymerized at high pressures and temperatures, which provides them greater mechanical properties that may make them desirable for usage in high occlusal forces Areas. (11) From a biomimetic viewpoint, these less brittle composite CAD/CAM blocks exhibit mechanical properties closely to human dentin ${ }^{(12)}$.

However, there is a lack of information about different extensions of endocrowns inside the pulp chamber in an attempt to increase the retentive surface area using a novel CAD/CAM material to restore extensively decayed premolars. So the aim of the current study was to compare the fracture resistance of single rooted upper premolar teeth restored with BC endocrowns with three different pulp chamber extensions ( $2 \mathrm{~mm}, 3 \mathrm{~mm}$ and $4 \mathrm{~mm}$ depth). The null hypothesis of this study was that the chamber depth would not affect the fracture resistance, nor failure type of upper premolar endocrowns.

\section{MATERIALS AND METHODS}

\section{Sample Size Calculation}

Sample size calculated depending on a previous study ${ }^{(13)}$ as reference. According to this study, the response within each subject group was normally distributed with standard deviation (21.6). If the true difference in the experimental and control means is (34.8), minimally the study needed (7) subjects in each group to be able to reject the null hypothesis that the population means of the experimental and control groups are equal with probability (power) (0.8). The Type I error probability associated with this test of this null hypothesis is $(0.05)$.

\section{Teeth selection}

Twenty four decay free extracted single-rooted upper premolar were collected for the study. A magnifying lens was used to inspect the teeth. 
After measuring the mesio-distal and bucco-lingual dimensions using a metal caliper crowns were selected to be with comparable dimensions.

\section{Teeth mounting}

Natural teeth were fixed in orthodontic acrylic resin blocks using a ready-made round plastic shape sample holder in a vertical direction using a dental surveyor, teeth were embedded in the resin blocks as the cemento-enamel junction (CEJ) is $2 \mathrm{~mm}$ above the resin.

\section{Endodontic treatment}

Access cavities were prepared with a round bur using a high speed hand piece under water coolant. The working length was measured using a K-file size 15 and a radiograph. Rotary system (Protaper, Dentsply, Maillefer, Ballaaigues, Switzerland) was used for manipulating root canal till files size F3 Irrigation was completed using sodium hypochlorite $4.2 \%$ in between files. Paper points (Dentsply-Maillefer, Ballaigues, Switzerland) were used for drying root canals. The prepared canal was built-in by using a master cone of a size F3 with a tug-back stroke to attain the full working length. The gutta-percha point was coated with Resin sealer (ADSEAL, MetaBiomed, korea). Excess gutta percha was detached with hot instrument and vertically condensed with a heated plugger. The access cavities were closed with temporary filling material (Cavit, 3M ESPE, Seefeld, Germany). All teeth were decoronated till $2 \mathrm{~mm}$ above the proximal CEJ using Computerized Numerical Control milling machine (C.N.C Premium4820, imes-icore, Germany). The CNC milling machine was accustomed to prepare the teeth with 90 butt margin design. The prepared teeth were haphazardly divided into three groups $(n=8)$ and received pulp chamber restorations to achieve symmetrical pulp chamber floors at depths of 2, 3, and $4 \mathrm{~mm}$ from the butt margin using a three-step etch-and-rinse adhesive (Optibond FL, Kerr Corporation, Orange,
CA, USA) and a dual cured flowable composite (Charmcore, Dentkist, Korea), then light cured by (Elipar S10, 3M ESPE, Seefeld, Germany). The preparation depth was standardized with periodontal probe and rubber stopper positioned taking the butt margin as reference point:

- Group I (Gr 2mm): 8 samples were prepared with $2 \mathrm{~mm}$ chamber extension.

- Group II (Gr 3mm): 8 samples were prepared with $3 \mathrm{~mm}$ chamber extension.

- GroupIII (Gr4mm): 8 samples were prepared with $4 \mathrm{~mm}$ chamber extension.

The CNC milling machine was attuned to prepare the premolars; all the internal walls were prepared to eliminate undercuts with an $8^{\circ}$ coronal divergence using a tapered diamond-coated stainless-steel bur with a rounded end (Hager and Meisinger $\mathrm{GmbH}$, Berlin, Germany) held perpendicular to the pulpal floor. An oval shape preparation was resulted with $(4.5 \mathrm{~mm}$ buccolinigual and $2.5 \mathrm{~mm}$ mesiodistal) dimensions ${ }^{(13)}$. All internal line angles were smoothed and rounded.

\section{Construction of Brilliant Crios CAD/CAM endocrowns}

First the preparations were scanned using Bluecam and the CEREC 3D software (version 4.3) for designing the endocrowns. Standardized endocrowns were milled with the CEREC MCX5 milling (Sirona, Bensheim, Germany) (MD distance between proximal contact areas: $6.56 \mathrm{~mm}$; distance between buccal and lingual faces: $8.88 \mathrm{~mm}$; height from the margin to the top of the buccal cusp: 7.42 $\mathrm{mm}$; height from the margin to the top of the lingual cusp: $7 \mathrm{~mm}$ ); this will assured standardization of the point of load application during testing; with $50 \mu \mathrm{m}$ spacer. Then the restorations were milled from Brillient Crios Blocks (Brillient Crios , Coltene, Switzerland). All endocrowns were cheeked over there corresponding teeth for seating. 


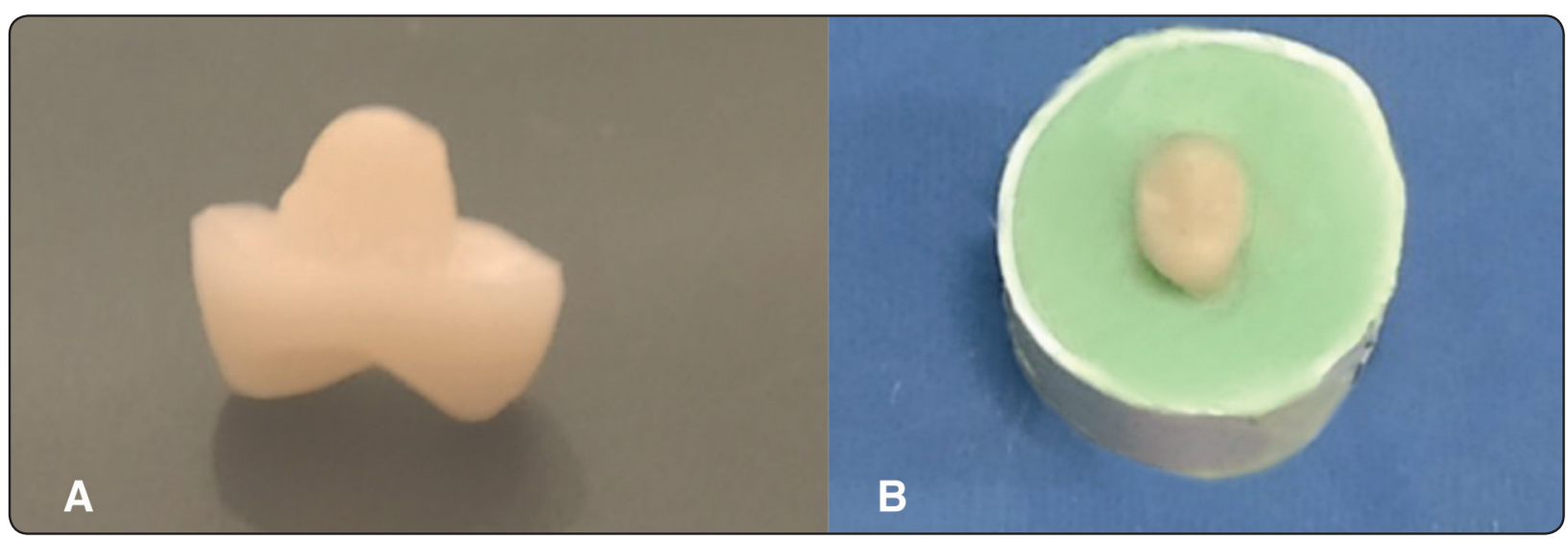

Fig. (1) a) Fitting surface view of endocrown after milling. b) : Occlusal view of endocrown after cementation.

\section{Bonding procedures}

Prior to cementation, endocrown fitting surfaces were treated according to the manufacturers' instructions. BC Endocrowns were sandblasted with 25-50 $\mu \mathrm{m} \mathrm{Al}_{2} \mathrm{O}_{3}$ powder $(0.15 \mathrm{MPa} / 1.5$ bar pressure). A silane coupling agent (3M ESPE Dental Products, St. Paul, MN, USA) was applied to the fitting surfaces and aid-dried for $60 \mathrm{~s}$, subsequently, adhesive agent was applied for $20 \mathrm{~s}$ and air-dried. The prepared teeth were cleaned with fluoride free pumice for 15 seconds, rinsed thoroughly with water for 15 seconds. The enamel of all preparations were etched for $30 \mathrm{~s}$ with $37.5 \%$ phosphoric acid (Ultra-Etch, Ultradent Products), rinsed, and dried. Self-adhesive resin cement (RelyX Unicem $2 \mathrm{Au}-$ tomix, 3M ESPE, Seefeld, Germany) was applied to the fitting surface of the endocrowns. Then each endocrown was bonded to its corresponding tooth with finger pressure, excess cement was removed immediately with a microbrush. A static load of 3 $\mathrm{Kg}$ was applied on the occlusal surface of the cemented endocrowns using a specially designed loading device, the endocrowns left under the static load for 5 minutes, then light cured with a LED curing unit (Elipar S10, 3M ESPE, Seefeld, Germany), at each surface for 20 seconds according to manufacturer's instructions. All samples were thermo- cycled for 5000 cycles between $5^{\circ}$ and $55^{\circ}$ with the dwell time of 30 s dwell time in a thermal cycling machine (C-501F, Will laboratory supplies LTD, Suzhou, China). Then, the samples were stored in a saline for 24 hours before testing.

\section{Fracture resistance determination}

Each sample was fixed in a universal testing machine (Model LRX-plus; Lloyd Instruments Ltd., Fareham, UK), Then a load was applied at a crosshead speed of $1.0 \mathrm{~mm} / \mathrm{min}$ and at an angle of $45^{\circ}$ to the long axis of the tooth using with a stainless-steel sphere (3.4 $\mathrm{mm}$ in diameter) contacting the palatal plane of the buccal cusps until fracture (Fig. 2). The fracture resistance of each specimen was recorded in Newton. All data were statically investigated.

\section{Fracture mode}

Following the fracture resistance test, fracture mode all samples were inspected visually and by Digital microscope (U500x Digital microscope, Guangdong, China). Each sample was snapped using USB Digital microscope with a built in camera connected with a compatible personal computer using a fixed magnification of X30. The samples were examined to decide different fracture modes: ${ }^{(14)}$ 


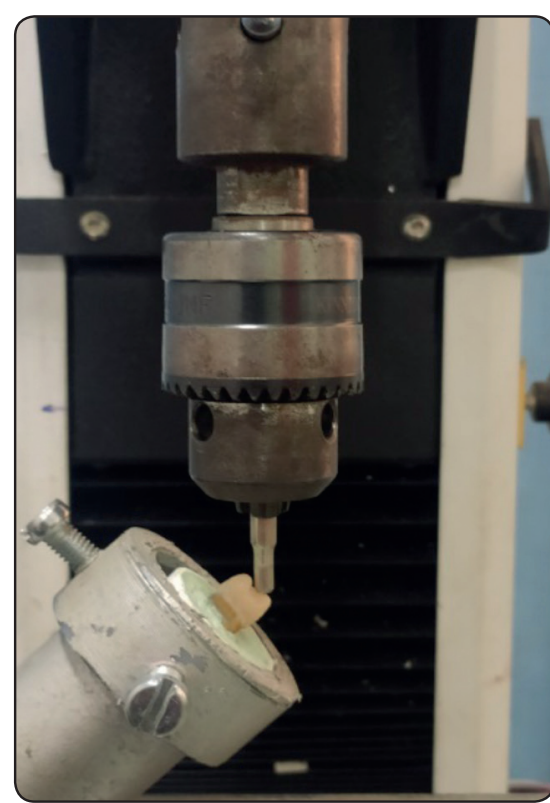

Fig. (2) Fracture resistance test with a Universal testing machine.

- Favorable Failures: repairable fractures of the teeth above cemento-enamel junction (CEJ) and fractures in the restorations. (Figure 5; a, b, c)

- Unfavorable Failures: non-repairable fractures below the CEJ including vertical root fracture. (Figure: $5 \mathrm{~d}$ )

\section{Statistical analysis}

Collected data were obtained through laboratory tests of Endo- Crown fracture resistance and fracture analysis. Data were statistically analyzed by Microsoft Excel ${ }^{\circledR}$ 2016, Statistical Package for Social Science (SPSS) ${ }^{\circledR}$ Ver. 24. and Minitab ${ }^{\circledR}$ statistical software Ver. 16. Fracture resistance data were revealed as mean and standard deviation while fracture analysis data were revealed as counts for further statistically analysis. Using One Way Analysis of Variance (One Way ANOVA) followed by Tukey`s post hoc test for multiple comparisons, Chi Square test was done for comparison of different failure modes.

\section{RESULTS}

\section{Influence of Preparation Depth on Fracture Strength values}

Regarding fracture resistance of different preparation depths $(\mathrm{mm})$; mean \pm standard deviation of group (I), group (II) and group (III) were $\left(475.6 \pm 69.92 \mathrm{~N} / \mathrm{mm}^{2}\right),\left(647 \pm 72.37 \mathrm{~N} / \mathrm{mm}^{2}\right)$ and $\left(353.9 \pm 61.02 \mathrm{~N} / \mathrm{mm}^{2}\right)$ respectively, Gr II recorded the highest mean value followed by Gr I, while $\mathrm{Gr}$ III recorded the lowest value.

Using One Way Analysis of Variance (One Way ANOVA) followed by Tukey`s post hoc test for multiple comparisons revealed that; there was significant difference between all groups as P-value $<0.05$, as listed in table (1) and showed in figure (3).

TABLE (1): Descriptive and Comparative Study of Fracture Resistance (N/mm2) of Endocrown Restorations according to Different Preparation Depths (mm):

\begin{tabular}{|c|c|c|c|c|}
\hline & $\mathbf{N}$ & $\mathbf{M}$ & SD & P-value \\
\hline Group (I) & 8 & $475.60^{\mathrm{a}}$ & 69.92 & \multirow{3}{*}{$0.000000115462 *$} \\
\hline Group (II) & 8 & $647.00^{\mathrm{b}}$ & 72.37 & \\
\hline Group (III) & 8 & $353.90^{c}$ & 61.02 & \\
\hline
\end{tabular}

N; Number, M; Mean, SD; Standard Deviation, P; Probability Level Means with different superscript letter in the same column were significant different using Tukey's post hoc test

*Significant Different

\section{Effect of Preparation Depth of Endocrowns on Failure Type}

Regarding fracture analysis of different preparation depths, Gr I showed highest repair ability percentage followed be Gr II and Gr III as listed in table (2) and showed in figure (4). 
For multiple comparisons of fracture analysis of chamber extension depths regarding repairable and non-repairable specimens using Chi Square test, there was significant difference between group (I) and group (II) from one side and group (I) and group (III) from other side as $\mathrm{P}$-value $<0.05$ listed in table

TABLE (2): Descriptive and Comparative Study of Fracture Analysis of Endo-crown Restorations according to different chamber extension Depths

\begin{tabular}{|c|c|c|}
\hline & Non- Repairable & Repairable \\
\hline Group (I) & $2^{\mathrm{a}}(25 \%)$ & $6^{\mathrm{a}}(75 \%)$ \\
\hline Group (II) & $6^{\mathrm{b}}(75 \%)$ & $2^{\mathrm{b}}(25 \%)$ \\
\hline Group (III) & $6^{\mathrm{b}}(75 \%)$ & $2^{\mathrm{b}}(25 \%)$ \\
\hline
\end{tabular}

Means with different superscript letter in the same column were significant different.

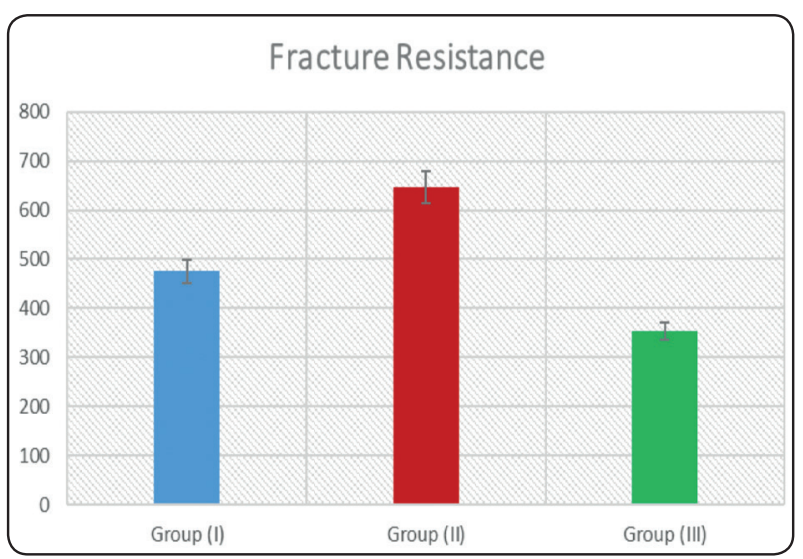

Fig. (3): Bar Chart revealing Descriptive and Comparative Study of Fracture Resistance of Endo-crown Restorations according to Different Preparation Depths
(2). Group (I) showed lower significant percentage than group (II) and group (III). On the other hand, there was insignificant difference between group (II) and group (III) as P-value $>0.05$ listed in table (3).Examples of fracture specimens are presented in (Figure 5)

TABLE (3): Multiple Comparative Study of Fracture Analysis of Endo-crown Restorations according to different chamber extension Depths

\begin{tabular}{|c|c|c|}
\hline $\begin{array}{c}\text { Preparation Depth } \\
\text { (I) }\end{array}$ & $\begin{array}{c}\text { Preparation } \\
\text { Depth (J) }\end{array}$ & P-value \\
\hline \multirow{2}{*}{ Group (I) } & Group (II) & $0.025^{*}$ \\
\cline { 2 - 3 } & Group (III) & $0.025^{*}$ \\
\hline Group (II) & Group (III) & 1.000 \\
\hline
\end{tabular}

P; Probability Level

Means with same superscript letter in the same column were insignificant different using Chi Square test. *Significant Different

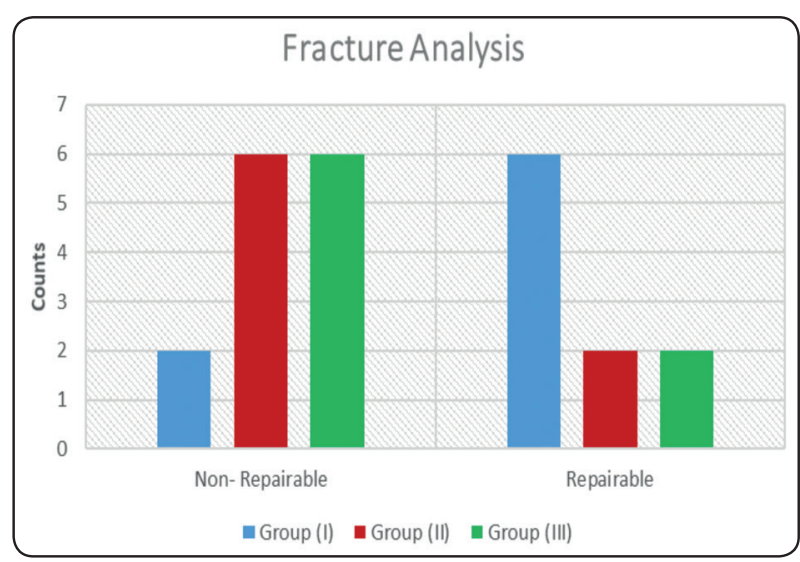

Fig. (4): Bar Chart revealing Descriptive and Comparative Study of Fracture Analysis of Endo-crown Restorations according to Different Preparation Depths 


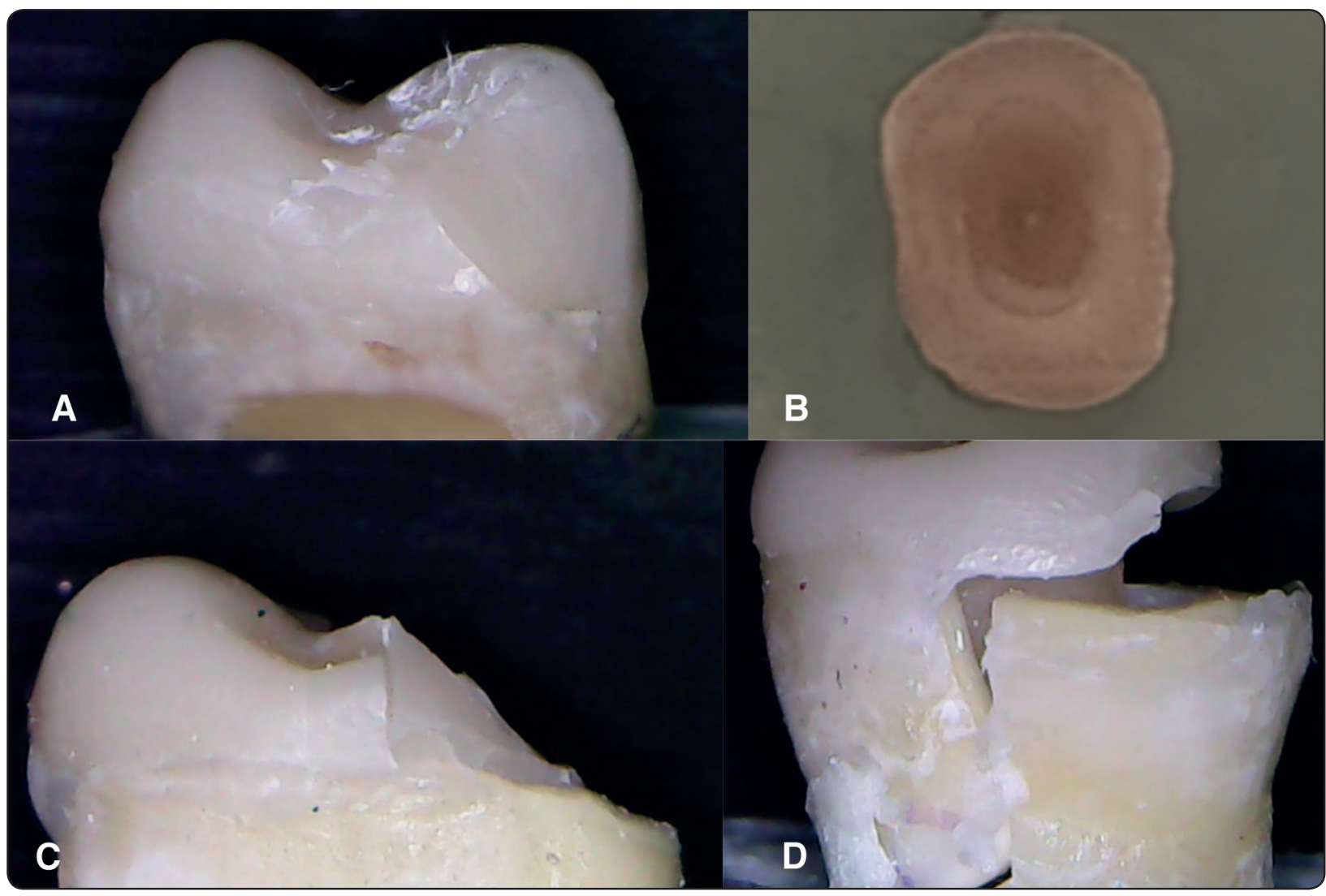

Fig. (5) : Represent mode of failures of endocrowns: a : Repairable failure : failure within the endocrown material. b: Repairable failure: adhesive failure; debonding of endocrowns and dentin. $\mathrm{c}$ : Repairable failure: failure within dentin above the CEJ . d: Irripairable failure: tooth fracture under the CEJ with vertical root fracture.

\section{DISCUSSION}

The null hypothesis of this study was rejected because a statistical significant effect was found regarding effect of preparation depth on both fracture resistance and failure type of upper premolars endocrowns.

Natural extracted teeth were used in this study because of their modulus of elasticity, bonding characteristics and strength that mimic clinical situation ${ }^{(15)}$. Attention was paid to the selection of teeth with comparable sizes, in which the teeth were selected to be of approximate similarity in size and shape with $10 \%$ maximum deviation from the determined mean to eliminate any extreme variation for the maxillary premolars.
Endocrown on maxillary premolars teeth were selected in this study because in previous study ${ }^{(16)}$ showed a non-satisfactory performance compared to molar teeth, according to bond strength and occlusal forces. This is due to smaller pulp chamber and the use of materials with low bonding strength on teeth.

Brilliant Crios (BC) was used in this study because it is an innovative submicron hybrid reinforced composite material with comparable modulus of elasticity of the tooth structure (10.3 GPa); it may improve the flexural strength by the stress absorption ability and improve the bonding to the tooth structure. ${ }^{(10)}$ This is not evaluated in any previous study.

All teeth were decoronated at right angles to the long axis and above the proximal CEJ by $2 \mathrm{~mm}$ 
to mimic the compromised condition of severely mutilated endodontically treated premolars. ${ }^{(17)}$

The depth of the pulp-chamber extension required by endocrown restorations has not been exactly defined. Bindl and Mörmann ${ }^{(9)}$ stated that while cavity depth could not be standardized precisely, it should sort between 1 and $4 \mathrm{~mm}$. It has been supposed that the occlusal stresses that occur during function are transferred to the pulp chamber walls. The deeper the pulp cavity and resulting intracoronal extension, the greater the surface area that can be utilized for adhesive retention and transmission of masticatory forces..$^{13}$ The present study explored the possibility of endocrowns on premolar teeth, especially with different pulp chamber depth.

The samples in the study were exposed to lateral occlusal loading to simulate the clinical condition; the forces in the posterior region are perpendicular, but are more angular in the premolar region. ${ }^{(18)}$ Moreover, in group function occlusion, maxillary premolars are exposed to repeated oblique occlusal forces that are translated into high lateral forces. This situation is the worst scenario for maxillary premolars as the risk of tooth fracture and restoration debonding is much higher. ${ }^{(16-19)}$

The specimens were exposed to 5000 thermocycling to clinically simulate the 6 months chewing condition, according to previous studies. ${ }^{(18)}$

Comparing between the groups, Gr $3 \mathrm{~mm}$ scored the highest mean fracture resistance value followed by $\mathrm{Gr} 2 \mathrm{~mm}$ and the lowest was scored by $\mathrm{Gr} 4 \mathrm{~mm}$. G3mm scored higher fracture strength than G2mm because it has deeper pulp chamber depth; there are more surface area for bonding, retention and stress distribution. These results are in agreement with a study of Lise et al. ${ }^{(20)}$ who investigate the biomechanical behavior of premolar endocrowns with two different intracoronal depths ; they found that $2.5 \mathrm{~mm}$ depth was more susceptible to failure than $5 \mathrm{~mm}$ depth under lateral occlusal loading. In addition, Dartora et al. ${ }^{(21)}$ found that larger extension of endocrowns inside the pulp chamber provided superior mechanical performance, improved stress distribution in endocrowns and superior fracture resistance. On the other side; the results of the present study was contradicted with the result of Ghajghouj and Faruk ${ }^{(22)}$ who found no significant difference of fracture resistance of endocrowns with 2 and $3 \mathrm{~mm}$ chamber extension. This contradiction could be attributed to the force axis used was at a $90^{\circ}$ angle instead of the $45^{\circ}$ for the fracture loading test in the current study. Additionally, the results of the present study was also contradicted with the result of Hayes et $\mathrm{al}^{(23)}$ who found that the 2 and $4 \mathrm{~mm}$ chamber extension groups demonstrated the highest fracture resistance, with the 3-mm group similar to the 2-mm group. This contradiction could be attributed to the dissimilarity of the natural teeth used; as mandibular molar teeth were used instead of the upper premolars in the current study.

The unexpected result for $\mathrm{Gr} 4 \mathrm{~mm}$ which scored the lowest fracture strength agrees with Hayes et $\mathrm{al}^{(23)}$ who found that endocrowns with a pulp chamber of $2 \mathrm{~mm}$ in depth showed a higher fracture resistance than teeth with $4 \mathrm{~mm}$ chamber depth. This could be due to scanning process, software design, and milling effects have an influence on the fitting accuracy of CAD/CAM restoration. Even with the major improvements in CAD/CAM technology systems, there might be some clinical problems. ${ }^{(24-26)}$ Even though the manufacturer information states that the CEREC Bluecam has a capture depth to 15mm (CEREC AC Operating Manual, Sirona), previous studies found that increasing the preparation depth negatively affected the accuracy of the captured image. ${ }^{(24-26)}$

Moving to repairing possibility of endocrowns restorations, $\mathrm{Gr} 2 \mathrm{~mm}$ demonstrated highest reparability percentage (75\%) followed by $\mathrm{Gr} 3 \mathrm{~mm}$ and $\mathrm{Gr} 4 \mathrm{~mm}$ which scored (25\%). The 2- mm pulp chamber extension group shown mostly restoration debonding accompanied with repairable tooth fracture. While seventy -five percent of the 3-mm and 4-mm chamber extensions groups demonstrated 
catastrophic (irreparable) fracture. This could be attributed to the pulp chamber depth of the preparations; in $\mathrm{Gr} 2 \mathrm{~mm}$ repairing possibility is the highest because the projection of the crown in pulp chamber is very small $(2 \mathrm{~mm})$ so debonding between the restoration and the tooth will occur without fracturing the root. This explanation was in agreement with Hayes et al ${ }^{(23)}$ who found that endocrowns with a pulp chamber of 3 and $4 \mathrm{~mm}$ in depth showed a higher catastrophic failure than teeth with $2 \mathrm{~mm}$ chamber depth, and the authors recommended that extension cavities not exceed $2 \mathrm{~mm}$ because deeper cavities tended to result in more irreparable fractures. Correspondingly Lise et al ${ }^{(20)}$ found that a shallow preparation with $2.5 \mathrm{~mm}$ intraradicular extention in premolars endocrowns decreased the risk of accidental root fracture than the $5 \mathrm{~mm}$ extention ; authors attributed this to the minimal removal of sound tooth tissue in 2.5 group that would weaken the tooth-root complex. Authors stated that deeper restoration designs ('5-mm deep endocrown') and the friction against the intraradicular walls provided extra macro-mechanical retention $^{(27)}$, while the retention following the '2.5$\mathrm{mm}$ deep endocrown' design relied mainly on pure adhesion. In this situation, the whole interface is located very close to the rotation center of the moment of force created by the oblique load, considering that the extension of $2.5 \mathrm{~mm}$ was located above the simulated bone level represented by the embedding resin and didn't fractured the root, which considered an advantage as de-bonded restorations could be recemented. Moreover the result of the current study is in consistent with Zhu et al. ${ }^{(28)}$ who explored by finite element analysis the effect of remaining tooth structure and restorative material type on stress distribution in maxillary endodontically treated premolars. Authors compared between three different extensions of restoration $(1.0 \mathrm{~mm}, 2.0$ $\mathrm{mm}$, and $3.0 \mathrm{~mm})$. They reported that the decreased extension of $(1 \mathrm{~mm})$ endocrown restoration resulted in decrease in the von Mises stress in coronal dentin and the risk of tooth fracture.

\section{CONCLUSIONS}

Within the limitation of this study, the following conclusions were drawn:

1) Brillient Crois endocrowns with 2 and $3 \mathrm{~mm}$ pulp chamber extensions provide greater fracture resistance than those with $4 \mathrm{~mm}$ as a treatment modality of endodontically treated maxillary premolars.

2) Brillient Crois endocrowns with 3- and 4-mm chamber extension demonstrated mostly catastrophic tooth fracture, whereas the 2-mm chamber extension displayed mostly repairable after failure.

\section{REFERENCES}

1. Loftus, J.J.; Keating, A.P.; McCartan, B.E. Periapical status and quality of endodontic treatment in an adult Irish population. Int. Endod. J. 2005, 38, 81-86.

2. Genovese, K.; Lamberti, L.; Pappalettere, C. Finite element analysis of a new customized composite post system for endodontically treated teeth. J. Biomech. 2005, 38, 2375-2389.

3. Sagsen, B.; Aslan, B.; Effect of bonded restorations on the fracture resistance of root filled teeth. Int. Endod.J. 2006, 39, 900-904.

4. Mörmann WH, Bindl A, Lüthy H, \& Rathke A Effect of preparation and luting system on all-ceramic computergenerated crowns International Journal of Prosthodontics; 1998: 11(4) 333-339.

5. Morgano SM, Hashem AF, Fotoohi K, Rose L. A nationwide survey of contemporary philosophies and techniques of restoring endodontically treated teeth. J Prosthet Dent 1994; 72(3):259-267.

6. Tzimas K, Tsiafitsa, Gerasimou P, Tsitrou E, Endocrown restorations for extensively damaged posterior teeth: clinical performance of three cases Restor Dent Endod. 2018 Nov;43(4):e38

7. Bindl A, Richter B, Mormann WH. Survival of ceramic computer-aided design/manufacturing crowns bonded to preparations with reduced macroretention geometry. Int $\mathrm{J}$ Prosthodont 2005;18(3):219-224.

8. Lin CL, Chang YH, Pai CA. Evaluation of failure risks in ceramic restorations for endodontically treated premolar with mod preparation. Dent Mater 2011; 27(5):431-438. 
9. Bindl A, Mormann WH ; Clinical evaluation of adhesively placed Cerec endo-crowns after 2 years--preliminary results. J Adhes Dent, 2014: 1:255-265.

10. Hampe R, Theelke B, Lümkemann N, Eichberger M, Stawarczyk B; Fracture toughness analysis of ceramic and resin composite, (2019) CAD/CAM material. Oper Dent 44:190-201

11. Matzinger M, Hahnel S, Preis V, Rosentritt M (2018) Polishing effects and wear performance of chairside CAD/ CAM materials. Clin Oral Investig 23:725-737.

12. Spitznagel FA, Horvath SD, Guess PC, Blatz MB Resin bond to indirect composite and new ceramic/polymer materials: a review of the literature. (2014) J Esthet Restor Dent 26:382-393.

13. Adel $\mathrm{S}$ et al. Fracture Strength of Hybrid Ceramic Endocrown Restoration with Different Preparation Depths and Designs IOSR Journal of Dental and Medical Sciences (IOSR-JDMS) e-ISSN: 2279-0853, p-ISSN: 2279-0861. Volume 18, Issue 5 Ser. 4 (May. 2019), PP 17-23 .

14. Salameh Z, Sorrentino R, Papacchini F, Ounsi HF, Tashkandi E, Goracci C, Ferrari M. Fracture resistance and failure patterns of endodontically treated mandibular molars restored using resin composite with or without translucent glass fiber posts. J Endod. 2006;32:752-5.

15. Potočnik B. Automated landmark points detection by using a mixture of approaches: the vole-teeth case. Signal Image Video Process. 2015 Jan 1;9(1):93-104.

16. Sornsuwan T, Ellakwa A, Swain MV. Occlusal geometrical considerations in all-ceramic pre-molar crown failure testing. Dent Mater 2011;27:1127-34.

17. Bassir MM, Labibzadeh A, Mollaverdi F (2013) The effect of amount of lost tooth structure and restorative technique on fracture resistance of endodontically treated premolars. J Conserv Dent 16: 413.

18. Heintze, S.D. Clinical relevance of tests on bond strength, microleakage and marginal adaptation. Dent. Mater. 2013, $29,59-84$.

19. Guo J, Wang Z, Li X, Sun C, Gao E, Li H. A comparison of the fracture resistances of endodontically treated mandibular premolars restored with endocrowns and glass fiber post-core retained conventional crowns. J Adv Prosthodont 2016;8:489-93.

20. Lise, D.P.; Van Ende, A.; De Munck, J.; Suzuki, T.Y.U.; Vieira, L.C.C.; Van Meerbeek, B. Biomechanical behavior of endodontically treated premolars using di_erent preparation designs and CAD/CAM materials. J. Dent. 2017, 59, 54-61

21. Dartora, N.R.; De Conto Ferreira, M.B.; Moris, I.C.M.; Brazão, E.H.; Spazin, A.O.; Sousa-Neto, M.D.; Gomes, E.A.E_ect of intracoronal depth of teeth restored with endocrowns on fracture resistance: in vitro and 3-dimensional finite element analysis. J. Endod. 2018, 44, 1179-1185.

22. Ghajghouj $\mathrm{O}$ and FarukS T; Evaluation of Fracture Resistance and Microleakage of Endocrowns with Di_erent Intracoronal Depths and Restorative Materials Luted with Various Resin Cements. Materials 2019, 12, 2528.

23. Hayes A, Duvall N, Wajdowicz M, Roberts H (2017) Effect of endocrown pulp chamber extension depth on molar fracture resistance. Oper Dent 42:327-334.

24. Gaintantzopoulou M, El-Damanhoury H. Effect of Preparation Depth on the Marginal and Internal Adaptation of Computer-aided Design/Computer-assisted Manufacture Endocrowns. Oper Dent. 2016;41(6):607- 616. doi:10.2341/15-146-L

25. Anadioti E, Aquilino SA, Gratton DG, Holloway JA, Denry IL, Thomas GW, \& Qian F : Internal fit of pressed and computer-aided design/computer-aided manufacturing ceramic crowns made from digital and conventional impressions Journal of Prosthetic Dentistry;2015: 113(4) 304-309.

26. Mously HA, Finkelman M, Zandparsa R, \& Hirayama H: Marginal and internal adaptation of ceramic crown restorations fabricated with CAD/CAM technology and the heat-press technique Journal of Prosthetic Dentistry;2014: 112(2):249-256.

27. W.H. Mörmann, A. Bindl, H. Lüthy, A. Rathke, Effects of preparation and luting system on all-ceramic computer-generated crowns, Int. J. Prosthodont. 11 (4) (1998) 333-339.

28. Zhu J, Rong Q, Wang X, and Gao X, Influence of remaining tooth structure and restorative material type on stress distribution in endodontically treated maxillary premolars: A finite element analysis J Prosthet Dent. 2017;117:646-655) 